\title{
Editorial
}

\section{The gender and sexuality issue}

For this themed edition, we take gender and sexuality as our overarching concern. Gender and sexuality are in the category of 'always already', present in the contexts of applied performance and drama education. Although, in some respects, gender and sexuality are present in all the work that is done with communities, this issue focuses on work where the issues of gender and sexuality rise to the surface. In this edition, we are profiling work that is about gender and sexuality as forms of identity, as modes of living and, in some cases, as means of resisting a gendered status quo where the issue is gender and sexuality.

When gender and sexuality become the issue, there is a consequential focus on such 'always already' modes in which applied practice might take place. In this endeavour, the approach that we have taken has not been restricted to a small set of genders and sexualities; rather the approach that we favour is one that addresses normative modes of gender presentation and sexuality based in dominant norms of heterosexuality. What we do consider below, however, is the way in which work done in queer and trans studies over the past few years has implications for all genders and sexualities. As such, the range of practices that are offered within this themed issue is broad and far-reaching. One cohering aspect of the work described here is a model of practice, reflected in queer performance work, that uses autobiography and participants' own lived experiences and stories and that seeks to destabilise assumptions related to gender and sexuality, as well as locating the construction of self and construction of community identity through performance. As Deirdre Heddon (2004) notes about autobiography's function within a contemporary culture 
of intolerance: 'Through their stories, then, the storytellers not only claim identities for themselves, but they may also attempt to rewrite what those identities mean ... The act of writing enacts the writer, bringing [her] in to existence as matter' (Heddon 2004, 221). This idea is useful as a context for lesbian, gay, bisexual, trans or queer-identified performers and participants - in that contemporary as well as historical cultures generate the need for community through marginalisation - and for a marginalised individual's insistence on the right-to-be as a gendered being:

Communities, as most often conceived, operate through a process of inclusion/exclusion. In order to have a community, there must be a boundary separating those who belong from those who do not (and the former relies on the latter). Shared narratives are one process of erecting and maintaining a boundary. (Heddon 2004, 221-2)

The sharing and showing of real stories, lived experiences and talking back is a general theme across the articles and reflections in this journal. Autobiography is a popular and familiar form for people who choose to tell their stories, whether in fiction, on film, on stage or in everyday life. Dean Spade (2006) talks about the strategic deployment of selfnarrative in relation to trans people's necessity to construct an 'appropriate biography' as they enter the medical system and begin the process of seeking treatment for gender reassignment. One way that power is manifest in authoritative discourse, or in discourses of authoring, as David Valentine comments, is the way that identity and personal narrative connect with institutions such as the medical or legal system. He says, 'identity is not something that simply arises from the self and its experiences but is the product of an ongoing process of meaning-making which draws on, and is drawn into, institutionalised categories of selfhood' (Valentine 2007, 223). He talks specifically about the ways that the self is narrated in relation to the state in order to make sense of violence, where a person 
harnesses the power of narrative force for political ends to appeal to particular agencies in order that transphobic violence is addressed. Of course, the other side to this, as Valentine remarks, is that in order to operate in this way one has to narrate oneself through those institutional frameworks, sometimes at the expense of other aspects of the self, such as race, class and sexual orientation.

We are keen to acknowledge here such relationships between institutional structures and the development of gender and sexuality. However people negotiate such structures, we are aware of a sense of agency that is commingled with the possibilities of that interaction. Work focused on gender and non-normative sexualities in queer theory over the past twenty years or so has often associated resistance to such structures with agency, and often the two have been equated (Puar 2007). Within the papers in this edition, the complex interaction with power structures also forms a cohering aspect when working with a focus on gender and sexuality in their normative and non-normative forms. For instance, narratives constructed from autobiographical storytelling, which tell of having a trans type of gender, can actively work against appealing for inclusion in the dominant narrative of having ' $a$ ' gender by challenging that dominant narrative. This notion differs from Heddon's concept of the relationship of gay narratives to the dominant account of sexuality, in which she suggests that people are specifically appealing for inclusion, using the idea that they too have a sexuality as well as heterosexual people. The performers, young people and project participants whose work is discussed within this edition are, in terms of gender, constructing narratives that draw on experiences of being other/in/of. Thus they acknowledge their own involvement in the construction of their identity and, moreover, how they negotiate with structural energies that regulate normative gender, 
both directly and subtly.

\section{Legibility and applied practice}

All of the applied practices that are discussed in this edition use the techniques and structures of applied theatre and performance to bring about a discussion of gender and sexuality in a way that is articulable to the community in which the presentation takes place. For the practices here, and in other places, the focus is, then, on legibility, in rendering gender and sexuality for a community in such a way that it nudges a solidified sense of gender identity, or that it constitutes in direct and indirect ways other binary-resistant forms of gender and sexuality as legitimate and legible - even if this is done through indirect representations of gender, through metaphor, analogy or allegory. Such work can be related to world-making strategies or, in a less grandiose way, is a creative resignification of the signs of heteronormativity. Crucially, in some of the work presented here, the focus is on some kind of attending to behaviours that sustain violence and systems of structural inequality as they relate to gender and sexuality.

Alexandra Sutherland, for instance, in this edition examines the performative and performed notions of gender and sexuality in relation to a prison theatre project which took place in a medium-security male prison in South Africa. Sutherland analyses some of the ways in which the project's participants experimented with performances of female or feminine roles, and also the complex ways in which gender and sexuality were played out beyond the theatrical frame. She asks, for example, how a young male prisoner's practising of alternative masculinities contributes to his sense of his own identity within the prison system, and also outside as a rehabilitated 'offender'. 
Such building of a sense of identity and its relation to operations of structural power is also explored in Aurora Murphy's paper, which discusses her own performance work based in Adelaide, Australia as an approach to engaging audiences in challenging normative notions of gender as they connect with practices of desire, power and sexual violence. She positions her participatory and public performance, Spreading the Love: the Bed Tour as a platform for people to develop shared discourses on negotiating ethical relationships and challenging some of the social and cultural scripts which perpetuate rape.

These scripts may also extend into whole communities. Jenny Hughes writes about a group of young men with experiences of homelessness, sex work and the criminal justice system who were participants in an arts and social welfare endeavour, the Men's Room project, in Manchester, United Kingdom. Hughes offers a descriptive account of the ways that a queer spatial practice questions normative notions of how particular spaces can be inappropriate for work with specific communities. We highlight in this edition that much of the applied work with a focus on gender and sexuality in some sense challenges heteronormativity, but Hughes presents this the 'other way around', as it were. That is, her contribution explores how the project dealt with the young men's use of support services. These services need to be organised in irregular ways, in order to engage with and support such communities; the needs of the group challenged the patterns of engagement that might usually be seen in a project of this kind. Through the project she explores, she remarks on a limitation of normative practice brought about by a project with these young men: as the young men are not being asked to interact with a service in a way that is normally structured through identification and inclusion, she indicates other rhythms in such a choreography of care. 
Likewise, Christine Hatton's piece, ‘Educating Rita and her sisters: using drama to reimagine femininities in schools', examines the way drama is used to challenge hegemonic structures, in this case narratives relating to gender for young adolescent girls. Hatton writes about girl-centred process drama, which seeks to investigate the complexities of $21^{\text {st }}$ century girlhood in a girls' school in Sydney, Australia. Through a focus on gender normativity, the lived experience of her group and connected complexity, Hatton perceives the challenges of such a task, not only for the girls and young women with whom she works, but also for the role of the teacher, upon which she reflects in a way that highlights that to question one agent of normativity is also to draw attention to another.

Similarly, focusing on upsetting normative forms of gendered identity, Nadine Holdsworth explores why and how Boys Dancing, a dance project in the West Midlands in the United Kingdom, has deployed rehearsal, dance and performance methodologies to overtly and covertly challenge normative discourses around boys, young men and masculinity. Holdsworth points out behaviours that groups of young men enact in order to shore-up normative masculinity, their efforts betraying anxiety both around how young men manage the prejudice of others and also around peripheral masculinities. Although she comments that the project would by no means completely resolve the difficulties of boys and dance in a UK context, Holdsworth makes the point that the project contributes to creating a regional culture of dance and seeds the next generation of male dancers, which in some way is a long game of resistance to the power of normative, or central, masculinities, through an art form and a space of creative play for young men.

Following this sense of the way that power, play and performance are interrelated and can be resistive, Tara Pauliny documents the drag king performances of Christie 
Whisman, an artist who was performing in Ohio, USA between 1999 and 2001, arguing that this work illustrates the political power in play. Whisman describes her own work as 'an educational process' and Pauliny presents an analysis of the performances as tools for demonstrating that sexuality and heternormativity, as well as race and class, are tethered to the construction and deployment of white masculinity.

Following these papers are a set of shorter pieces that focus on specific moments within drama education and applied performance practice, where gender and sexuality were at the forefront of the work in various ways. Liselle Terret writes about the use of the technique 'mantle of the expert' when working with a group of primary school children on a process drama inspired by David Walliams' Boy in a Dress. Lorna McGinty shares moments from a drama project involving young transgender and genderqueer people. Miranda Young-Jahangeer writes about a performance event celebrating Women's Day in Westville Female Correctional Centre, Durban, KwaZulu-Natal, South Africa. Sherry Teitelbaum describes the ways that the technique 'role of the wall' yielded productive opportunities for identifying and challenging stereotypes relating to age and sexual orientation, in a project which worked with participants aged between 18 and 81 . Victoria Shaskan offers extracts from an interview with the performers of Collective Artistes' theatre production $Z /$ he: [noun] Undefined, where the performers talk about autobiographically-inspired narrative in the piece, and the reception the work receives from young people who identify as lesbian, gay, bisexual, transgender and genderqueer.

\section{Issuing identification}

This identification with a gender or a sexuality and its exploration in performance is 
the issue of the edition. However, we wish to allow a bit of play with the word 'issue', in the sense that 'to issue' is also 'to bring about' or 'to produce' something into existence. In the areas of gender and sexuality, especially since the development of queer in the 1990s, such bringing about has generated a focus in the field on gender as being in a large way culturally constructed. Although such social construction described by $1990 s^{\prime}$ queer is by no means a unique turn in the study of gender, the emphasis brought by Judith Butler's work to the area has placed a stress on the performativity of gendered subjectivity, seeing gender as an effect of corporeal stylisations that exist within a particularly restrictive heteronormative grid of possibilities constructed in and through a heterosexual imperative. Some applied theatre and drama education practitioners have responded to this development by working in some way to use performance and drama to legitimate, bring about, or issue forth modes of living that resist the heteronormative. However, it is not only in the creative arts that there has there been a growth in performances that seek to express non-normative genders and sexualities and in some sense legitimate them. Also, since the 1990s there has been a legislative and larger cultural response to people living lives in which non-normative gender and sexuality plays a part. There was a boom, for example, in the production of research and academic writing on trans in the 1990s, partially in response to Butler's work and the reprinting of The Transsexual Empire: The Making of the She-male (Janice Raymond, original publication 1980, reprinted 1994). There are significantly fewer academic writings that take account of and comment upon transgender histories and experiences outside the United States, ${ }^{1}$ although interest began to grow elsewhere in the mid-2000s as the result of a developing social agenda around rights and responsibilities. ${ }^{2}$ Recent and significant changes in the United Kingdom's legislation are beginning to impact on lived experiences and, interestingly, are being explored 
through performance practice. For instance, in the United Kingdom, the Gender Recognition Act (GRA) 2004 has been introduced, and the Equality Act 2010 includes the category of Gender Reassignment to include transsexual and transgender people, such that gender reassignment is now a characteristic that is protected by anti-discrimination legislation. ${ }^{3}$ At the same time, there have been community performances that have engaged with or lobbied for a change in legislation. For example, Jason Barker, an artist based in London, United Kingdom, works with theatre and performance to acknowledge and make public the diversity of transgender masculinity and trans male lived experiences, in works such as There is No Word for It (2009), which was inspired by Eve Ensler's Vagina Monologues project. The project 'drew on transcripts from interviews with a number of female to male trans people and celebrates trans male sexuality. The monologues explore aspects of lived experiences including childhood and family, transitioning bodies, growing old, male privilege, sex and genitalia' (McNamara 2011, 101).

However, it is significant that applied performance practice that engages with people who identify as trans is relatively scarce, and examples of where that practice is written about, even more scarce. That scarcity is reflected in this edition. Our motivation for generating a themed issue is one way of contributing to a corpus of applied practice where gender diversity and 'alternative' sexualities are critical to the work, because the processes of creating drama, theatre and performance in applied contexts are also processes of always-creating gendered identities. In drawing together a range of writing about practice, we are able to contribute to the archiving of these kinds of performance practices that tend to be relatively undocumented. We recognise that, although all work is in some ways gendered, and we reflect a range of those gendered identities in this edition, there is a particular under-representation of work that 
engages with and reflects on applied practices in and with trans communities. Although the work in this edition focusses fully on gendered bodies, there is not much work reflected on that looks at how non-normative gender functions in projects that are specifically designed for working with the trans community. This is intriguing, because there is such work taking place. In 2012, Rose Walker (a development worker with the Transition Support Service in Edinburgh) ran a workshop, Finding Your Walk, which was facilitated by a qualified dance and movement therapist. The objective was to support trans people to feel more physically confident with their body, how they walk and how they move in social environments. This support service is part of the LGBT Centre of Health and Wellbeing in the city (www.lgbthealth.org.uk). In October 2008, the Scottish Transgender Alliance started running a transgender creative expression group called TRANSforming Arts. They have offered visual arts workshops in partnership with the Glasgow Gallery of Modern Art and a residential writing retreat among other projects. The group's principal facilitator is playwright Jo Clifford. Participants' work has been performed in various public spaces and as part of the Transgender Day of Remembrance in 2008 and LGBT History Month in 2009 (http://www.scottishtrans.org/Page/STA TRANSforming Arts Group.aspx accessed $\underline{15 / 02 / 13})$. For a further description of some of this work in the United Kingdom context, see Stephen Greer (2012).

\section{Gender, performance and the queer turn}

Reflecting on the boom in the 1990s around gender fluidity, Judith Butler in Undoing Gender (2004) notes that in her most influential work, Gender Trouble (1990), she under-thought or under-developed the idea of how gender is related to performance. Her work in the $1990 \mathrm{~s}$ chose drag as the exemplar mode of thinking about the performativity of gender. Butler 
indicates 15 years or so later that her real focus in thinking about drag was much more related to communities and the ways in which they have used gender in performance as a way of articulating 'collective terms' (Butler 2004, 216), of authoring through a community making performance for itself a:

cultural life of fantasy that not only organizes the material conditions of life, but which also produces sustaining bonds of community where recognition becomes possible, and which works as well to ward off violence, racism, homophobia, and transphobia (Butler 2004, 216).

Thus, performance for Butler plays a part in the ways that communities might come together and, as it were, play out intelligible subjectivities, which to those outside those communities might be less than clear articulations of a liveable life.

As such, queerness in the fields of gender and sexuality needs some unpicking and requires consideration of how it might be present in, and useful for, applied practice and drama education. There is an argument that sees queer as the manifestation of a poststructuralist ideal of a constantly deferred play of signification, that upsets the logic of identity per se, and its uses are powerless in the face of authorities that might be frankly operating power in direct and violent ways. Yet, this never-ended quality is only one way of thinking queer, theorising it and living it, a 'ludic' queerness (Freeman 2010). In other visions of queerness, such as that described by Max Kirsch (2000) for instance, there is a Marxist-influenced arm of queer that does look directly to the material conditions of queerness; others such as Cathay Cohen 'implicate queer politics in an intersectional model' (Puar 2007, 23). Likewise, other theorists 'look to queerness as a challenge predominantly to heteronorms' (Puar 2007, 23) and, whilst privileging such a resistance as Puar says, may underplay or erode the importance of race and class in structural inequalities. To what 
extent a focus on non-normative gender and sexuality encourages an effacement of other socially indelible markers of class and race is something that has formed a number of discussions in queer politics over many years. However, as academics and theorists have been nuancing readings of what such arms of queer theory bring about (as well as their shortcomings), younger people have begun to claim a solid queer identity. In some ways this claiming of queer as a unitary identity might be seen as a hegemonisation of queer's radicalness because, in some queer thinking, the purpose of queer is to undermine such unitary identities. Claiming the identity of queer, impossible though it may seem to some parts of queer theory, is about a lived experience of a non-normative gender or sexuality. In a world where it is still possible to risk ostracism, imprisonment and even death by claiming or enacting a non-normative gender or sexual identity, queer takes on a particularly urgent energy, in that its ludic quality in such restrictive situations is not only a source of resistance, but also through performance a collective response to making life liveable.

The papers for this edition centre on reflections and analyses of the way in which genders and sexualities interact with narratives and structures of normativity. Such a focus can expose the ways in which applied practices and drama education have sought, or not, to make plain the ways in which normativity is embedded in these practices. This is an important question of efficacy for applied performance in work with people claiming nonnormative genders and/or sexualities, but it also indicates a focus on the places and structures where such discourses of normativity circulate.

Normativity, of course, is not stagnant. That is, normativity, expressed as what can be seen to be intelligible, is an ever-changing landscape. Likewise, the non-normative is mobile in a similar way. For instance as we have mentioned, in the context of the United 
Kingdom, lesbian, gay and transsexual people have made headway in gaining franchise in government policy. This is also reflected throughout other parts of Europe and the world. Yet, at the time when Butler was writing her groundbreaking text, such protections were by no means so prevalent. As described above, trans people in some parts of the world are protected by law in some aspects of their lives: in these cases, the normative, here depicted as something that might be related to political franchise, has indeed responded to protect trans people from discrimination and harassment. However, such gains have not always been easy to achieve. What is clear in this context is that the normative and the nonnormative are in a dynamic relationship which involves power, legibility and the extension of tolerance in specific ways. How applied practice has engaged with the fluidity of normativity is of particular interest for this edition, as it reveals the strategies, tactics, techniques and approaches that unpick the power in the normative and render seemingly unintelligible non-normative gender and sexualities visible in various ways. Such normativity as an energy in itself is not restricted to those positions or places in institutional power where the normative rules. The trans community has its conservative elements (Butt 2008) and the queer community has developed both what Lisa Duggan calls homonormativity (Duggan 2006) and what David Eng refers to as exclusionary practices (Eng 2010). What should be remembered here for this edition is that the non-normative does not always connote a progressive agenda. Rather, the power games that are present in any gendered relationship are also present in the communities where one might expect to see fewer of them. These power relations often revolve around representation and legibility, be that in the social, legal, political or creative contexts. What the papers and descriptions of practice contained within this edition comprise is a sense that to render something legible is 
in some way a political act. Whether that 'making at issue' is the legibility of an othered type of gendered lived experience, or using work to shed some light upon the maintenance of normative gender and its scripts, such efforts have as part of their fuel a sense of change through recognition. The politics of recognition for this set of writings are a crucial undergirding that issue forth, or make at issue, gender and sexuality.

\section{Notes on editors}

Stephen Farrier is a senior lecturer at the Royal Central School of Speech and Drama. His work is focussed on gender and queer performance practices. He is particularly interested in how identities can be related and interact with theatrical forms and performance traditions.

Catherine McNamara is co-founder of Gendered Intelligence and Pro-Dean (Students) at Royal Central School of Speech and Drama. Catherine teaches on various undergraduate and postgraduate courses at Central as well as supervising at Doctorate level. Catherine's applied theatre practice and research often engages with trans and queer-identified young people.

1. For instance, see the Transgender Studies Reader (Stryker and Whittle, 2006) which is a collection of essays by approximately 50 authors, at least 35 of whom are American or have worked primarily within American medical or academic institutions.

2. Publications emerging include Stephen Whittle's Engendered Penalties: Transgender and Transsexual People's Experiences of Inequality and Discrimination (Whittle et al. 2007), the 
Department of Health's series of publications including Bereavement: A Guide for Transsexual, Transgender People and Their Loved Ones (Whittle \& Turner 2007) and A Guide for Young Trans People in the UK (Gendered Intelligence and GALYIC 2007), and Sally Hines' TransForming Gender: Transgender Practices of Identity, Intimacy and Care (2007).

3. The degree of legal recognition provided to transsexual people varies widely throughout the world. In January 2013, Sweden repealed a law which had previously made sterilisation compulsory for people undergoing gender reassignment surgery, in order for the state to recognise their gender identity. The Constitution of South Africa forbids discrimination on the basis of sex, gender and sexual orientation (amongst other grounds). The Constitutional Court has indicated that sexual orientation includes transsexuality. In 2003, a law was passed in Japan to enable transsexual people to change their legal sex; however, there are conditions which demand that the applicants be both unmarried and childless. In Malaysia, a judge would exercise their discretion on a case-by-case basis in granting legal status to a transsexual person. The legal recognition of trans people is by no means constant throughout the world. 


\section{References}

Butler, Judith. 1990. Gender Trouble: Feminism and the subversion of identity. London, Routledge.

Butt, Gavin. 2008. Hoyle's humility, (interview with David Hoyle). In Dance Theatre Journal 23, no. 1: 30-34.

Eng, David. 2010. The Feeling of Kinship: Queer liberalism and the racialization of intimacy, Durham and London: Duke University Press.

Gendered Intelligence and GALYIC. 2007. A guide for young trans people in the UK. London. Department of Health. http://genderedintelligence.co.uk/trans-youth/resources (accessed 20.12.12)

Greer, Stephen. (2012) Contemporary British Queer Theatre. Palgrave: Basingstoke.

Freeman, Elizabeth. 2010. Time Binds: Queer temporalities, queer histories. Durham and London: Duke University Press.

Heddon, Deirdre. 2004. Performing lesbians: Constructing the self, constructing the community. In M. Gale (ed.), Auto/biography and Identity: Women, theatre and performance. Manchester University Press: Manchester.

Hines, Sally. 2007. TransForming Gender: Transgender practices of identity, intimacy and care. Bristol: The Policy Press.

Kirsch, Max. 2000. Queer Theory and Social Change, London: Routledge.

McNamara, Catherine. 2011. Using men's changing rooms when you haven't got a penis: the constitutive potential of performing transgendered masculinities. Performing Ethos: An 
International Journal of Ethics in Theatre \& Performance (Special Issue: Queer Publics) 2, no.

2: 95-107

Puar, Jasbir, K. 2006. Terrorist Assemblages: Homonormalisation in queer times. Durham \& London: Duke University Press.

Raymond, Janice. [1980] 1994. The Transsexual Empire. London: The Women's Press.

Spade, Dean. 2006. Mutilating gender. In Susan Stryker and Stephen Whittle (eds). The Transgender Studies Reader. New York: Routledge.

Stryker, Susan and Whittle, Stephen (eds). 2006. The Transgender Studies Reader. New York: Routledge.

Transfabulous and girlboy. 2009. There is no word for it. London: Soho Theatre. 18.06.09.

Valentine, David. 2007. Imagining Transgender: An ethnography of a category, Durham:

Duke University Press.

Whittle, Stephen and Lewis Turner. 2007. Bereavement: A guide for transsexual, transgender people and their loved ones. London: Department of Health http://www.dh.gov.uk/en/Publicationsandstatistics/Publications/PublicationsPolicyAndGui dance/DH 074259 (accessed 14.09.08).

Whittle, Stephen, Lewis Turner and M. Al-Alami. 2007. Engendered Penalties:

Transgendered peoples' experience of inequality and discrimination, communities and local government publications, http://www.pfc.org.uk/pdf/EngenderedPenalties.pdf (accessed 20.12.12) 